terminal. The subdural haematoma both in the case quoted and in the other was silent.

This is a small and somewhat artificial group which shoulu be regarded aetiologically as a gross manifestation of the general haemorrhagic tendency in liver failure.

\section{Peripheral Neuritis}

In the Arakan in 1944 there was a small and short-li-ed outbreak of peripheral neuritis which coincided precisely in time with the development of jaundice in each case. This outbreak will be reported elsewhere by Byrne, who considers, with sume reason, that the symptoms and signs of peripheral neuritis were due to the emergence of a neurotropic element in the virus of infective hepatitis. We have observed one such case:

A British private aged 38 complained of a painful heel on July 26 , 1944. He had cellulitis of the heel, which cleared up by Sept. 20 . There was no open ulcer. He then noticed difficulty in walking (the difficulty involved both legs), and a week later he developed infective hepatitis. Jaundice was persistent, the weakness of the legs became gradually worse, and the arms became weak also. On Nov. 12 (the last day on which he was seen, as he developed amoebic dysentery and had to be evacuated) examination showed normally reacting pupils, no cranial nerve lesion, general weakness of the upper limbs with absent tendon reflexes, and general weakness of the legs . with absent knee- and ankle-jerks. There was wasting of the dorsiflexors, with blunted touch sensation on the legs and slight Rombergism.

It seems doubtful whether the peripheral neuritis in this case was causally related to the infective hepatitis. Hurst (1943) observed similar cases in Gallipoli in the 1914-18 war, and it is by no means certain that they did not represent the simultaneous occurrence of two fairly common diseases.

\section{Summary}

The neurological complications of infective hepatitis are reviewed.

Four main groups are illustrated by cases observed in Assam and Bengal in 1944.

It is concluded that neurological changes may appear in association with infective hepatitis due to a number of causes, most of which are still a matter for speculation.

Our thanks are due to Lieut.-Col. G. A. Ransome, I.A.M.C., for records of Cases 1, 2, and 3, analysed in the Table.

\section{REFERENCES}

Biemond, A., and van Crefeld, S. (1937). Arch. Dis. Childh., 12, 173.

Greenfield, J. G., Poynton, F. J., and Walshe, F. M. R. (1924), Quart. J. Med.,

Hawksley, J. C., and Lightwood, R. (1934). Ibid., 27, 155

Hurst, A. F. (1943). Medical Diseases of War, Arnold, London.

Lucké, B. (1944). Amer. J. Path., 20, 471.

Waggoner, R. W., and Malamud, N. (1941). Trans. Amer. neurol. Ass., 67, 45

\section{A TRICK TEST TO DETECT NIGHT- BLINDNESS “MALINGERERS"}

BY

\section{E. EPSTEIN, M.B., B.Ch., D.O.M.S. Major, R.A.M.C}

AND

\section{S. A. HUGH LESSER, M.A., M.B., B.Ch.} Capt., R.A.M.C.

The tests that have so far been evolved to examine scotopic vision-pentagon, hexagon, and the various adaptometers-are all subjective in nature and therefore demand the full co-operation of the subject. From the military point of view this is of little value in eliminating the few genuine cases of night-blindness from the many who simulate the condition. To help in sifting these cases the following test was devised and preliminary experiments have been carried out.

It was thought that if it could be shown that the subject was co-operating fully, then more reliance could be placed upon the subjective results of one of the above-mentioned night-vision tests. A mass of experimental data (Hecht and Williams, 1922 ; Hecht and Mandlebaum, 1939; McDonald, 1940 ; Mandlebaum, 1941) indicates that red light stimulates the cones of the retina only and that the rods are unaffected. On this basis, subjects with normal central vision-that is, adequately functioning cones at the macula-should be able to identify a pure red light at minimal intensity even if the rest of the retina is diseased or defective.

Expe-iments performed by us have shown that the minimum threshold for pure red falls within a very narrow range of intensity of illumination (Fig. 1). An individual with defective night vision but with normal cones-that is, normal macular function-should theoretically be able to see red light within this narrow normal range of minimal intensity. This hypothesis has been confirmed by the few cases of early retinitis

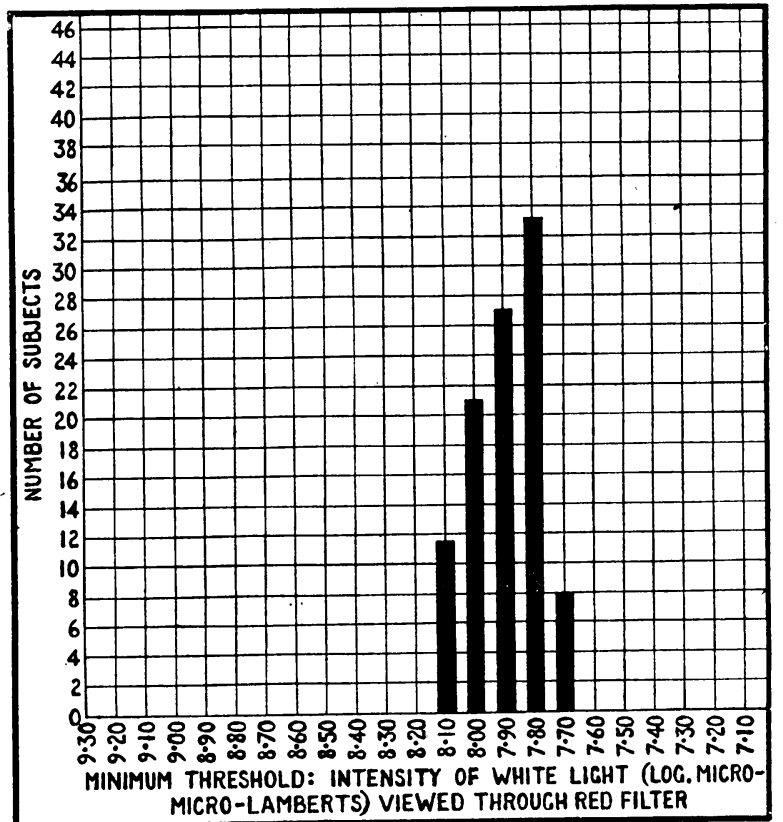

FIo. 1.-Range of minimum threshold for red light of 100 subjects chosen at random and including those with hypermetropic and myopic errors of refraction.

pigmentosa, diffuse choroido-retinitis (maculae unaffected), and advanced glaucoma with very contracted fields but good central vision which we have so far been able to test. One possible exception, suggested by the literature (Wald, Jeghers, and Arminio, 1938; Wald and Steven, 1939 ; Hecht and Mandlebaum, 1939; Mandlebaum, 1941)-for we have not been able to find such a case-is severe nutritional deficiency (vitamin A), because it is reported that in experimentally induced vitamin $\mathbf{A}$ deficiency the cone threshold for white light, and therefore we presume the red threshold as well, is raised. In practice, however, this exception can be dismissed, as this condition cannot arise on Army diets and would, in addition, show other well-marked features. Finally, it is necessary that known cases of night-blindness (familial) with no signs of disease or abnormality of the fundi should be tested to ascertain if such cases fall within the above established normal range of minimal thresholds. This would substantiate the universal application of the test.

\section{Method}

The test evolved is briefly as follows. The individual who complains of night-blindness at the out-patient clinic is given a careful routine examination including colour vision, then placed in a dark room, given dark goggles, and left to darkadapt for 20 minutes. Other patients are seen meanwhile, so that no time is wasted. After 20 minutes' adaptation the "night-blind" patient is asked to state when he can just see the faint red light which is shown him and increased gradually in intensity; as soon as he can see the light it is dimmed and the test repeated a few times until a constant result is obtained. It is simple to deduce whether the patient is co-operating or not. The general procedure of the test suggests to the subject that his night visual ability is being tested, and the malingerer reasons that he must not admit seeing the light until it is very bright ; but this, of course, does not tally with the results of the general.routine investigation, which shows that he has normal macular function. Further, the several readings 
taken often give inconstant results in this type of case, as it is difficult for the malingerer to judge an equal brightness intensity each time.

This test takes up about five minutes of the operator's time. When a result within the normal range is obtained it can be assumed that the patient is co-operating, and one of the tests of scotopic vision can be performed with reliance upon the results.

The apparatus used is Crookes's adaptometer 1944 (Fig. 2) (Godding, 1945), which consists of a screen illuminated by a

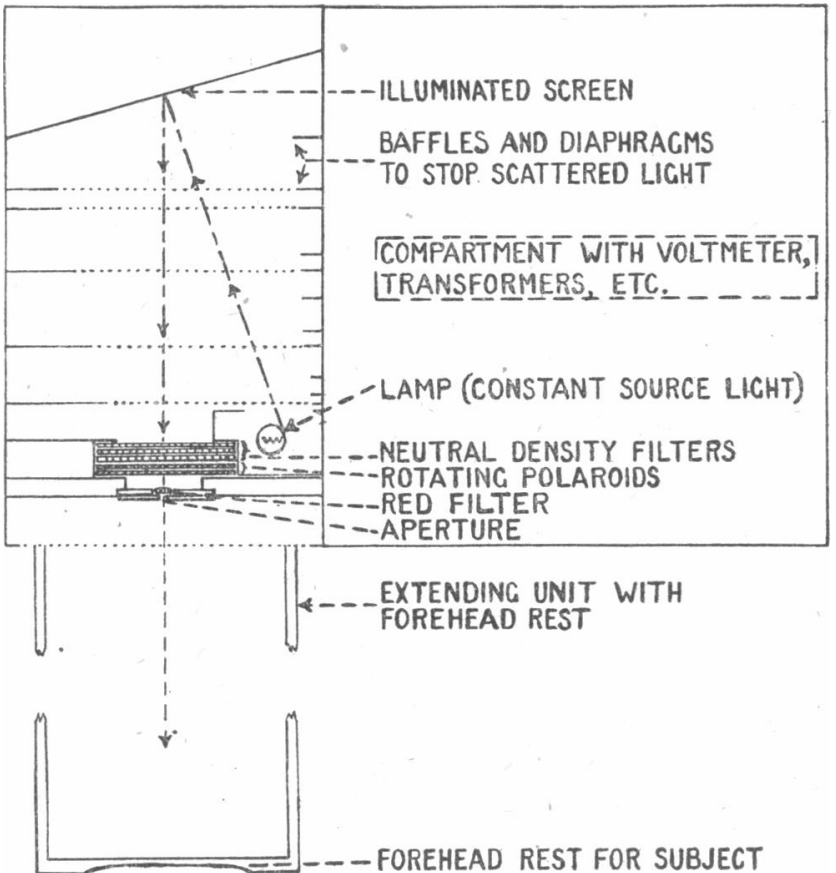

Fig. 2.-Horizontal section of Crookes's adaptometer 1944.

constant source. The intensity exhibited is varied by neutral density filters and rotating polaroids placed between the screen and the observer. This has been calibrated by the National Physical Laboratory. The red filter used is Dufay-Chromex No. 2257, which transmits the longer waves of red light as shown in Fig. 3-i.e., 680 to $720 \mathrm{~m} \mu$. Of the various filters tried

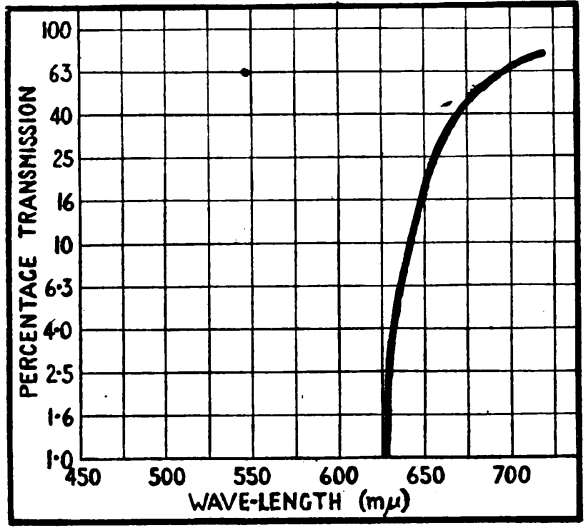

Fig. 3.-Transmission of Dufay-Chromex filter No. 2257.

this was found to be the best, as it "crossed the threshold coloured," the other filters allowing the transmission of shorter waves, which were perceptible as a faint grey before the light was seen as red, thus making it difficult to determine the threshold and giving a wider variation in the normal range. A square aperture, subtending an angle of $1^{\circ}$, diagonally, at the testing distance, is used in front of the filter, and the patient is placed in position and shown this before the test so that he knows where to look and can fix on it. A square aperture is used as suggested by Sloan (1939) to avoid confusion with the vague sensations of light experienced by subjects at threshold values. A $1^{\circ}$ aperture at threshold values for red light stimulates, only the macula and is not appreciated by paramacular regions.

The subject is first tested without spectacles. It was noted that many cases with high refractive errors gave subnormal results without their glasses and normal readings with them. The value of spectacles in these instances was not only refractive but helped maintenance of fixation, for the esophoria of hypermetropes and exophoria of myopes became manifest in the dark. The more observant of these subjects volunteered that their eyes seemed to have wandered in the dark and that they suddenly saw the red light when they moved their eyes a little to one side. Cases with small refractive errors-less than +3 or $-3 D$ - usually gave the same result with or without glasses; or those cases giving a very good result without glasses might give a slightly worse reading, though well within normal, with the spectacles. No doubt the explanation of this is the absorption and reflection by the lenses of some of the incident light.

\section{Illustrative Case Histories}

Case 1.-Lieut. A. had complained of night-blindness in 1943, when he was examined at an ophthalmic centre and a very poor result $(1 / 5)$ was obtained with the Army pentagon test. He was considered bad enough to be excused night duties, but was left in Category A. He was seen in Jan., 1945, after posting to a new unit, the authorities of which considered it incongruous for an officer to be Category $\mathbf{A}$ though deemed so night-blind as to be excused night duties. Routine examination revealed no abnormality, but, tested with the red light, he admitted seeing it only when it was very bright and well outside the normal range. Before taxing him with this incongruity he was referred to a psychiatrist-Major McCarthy, R.A.M.C.- who diagnosed an extremely abnormal state bordering on psychopathy.

Case 2.--Lieut. B. had always had difficulty in the black-out. When with the B.L.A. he found that one relatively dark night he was unable to see to drive, and had to employ a driver, who managed quite easily. The fundi showed numerous small retinal cysts (Blessig) which reached to well behind the equator. The red test gave a normal result. The dark-adaptation curve showed a slow rate of adaptation and a final threshold definitely higher than normal. This officer was considered to be handicapped in the dark; he was suitably categorized.

Case 3-Gnr. C. had difficulty in getting about at all in the blackout. Routine examination, red test, and dark-adaptation curve were all normal. Further questioning revealed the story of an accident during the first month of the black-cut, when he had run into the back of a stationary lorry with no tail thght and had severely bumped his right eyebrow. He then realized that the pain which he had been experiencing above his eyes in the black-out was a "memory" of this accident. Reassured of his perfect sight, he went away feeling much happier. His medical officer was advised to refer him to a psychiatrist if his symptoms recurred. A follow-up four months later elicited that he had not complained about his eyes and was performing his duties satisfactorily.

Case 4.-Pte. D. had difficulty in driving in the black-out. Red test and dark-adaptation were normal. Close questioning revealed that he disliked driving at any time. He was referred to the psychiatrist, who reported a severe anxiety neurosis necessitating institutional treatment.

Case 5.-Sign. E.'s eyes were normal. The red test showed noncooperation. Further questioning revealed nothing of note. His medical officer was notified to disregard all complaints of visual defect at night.

We wish to thank Brig. Sir Stewart Duke-Elder for permission to publish this paper, and we are grateful to the Crookes Laboratories for the loan of their adaptometer.

\section{REFERENCES}

Godding, E. W. (1945). Proc. roy. Soc. Med., 38, 155

Hecht, S., and Mandlebaum, J. (1939). J. Amer. med. Ass., 112, 1910.

Hech and Williams, R. E. (1922). J. gen. Phys., 5,

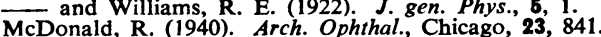

McDonald, R. (1940). Arch. Ophthal.,

Mandlebaum, J. (1941). Ibid., 26,

Wald, G., Jeghers, H., and Arminio, J. (1938). Amer. J. Physiol., 123, 732

Wak, G., Jeghers, H. (1939). Proc. nat. Acad. Sci., 25, 344

The first issue of a new American periodical, Ouarterly Review of Psychiatry and Neurology, is now in preparation. The editorin-chief is Dr. Winfred Overholser, and the quarterly will be published by the Washington Institute of Medicine, 1720, M Street, N.W., Washington 6, D.C. (annual subscription \$9.00). 